\title{
Sharing Progress in Neonatal (SPIN) Lung and Brain
}

\author{
Incorporating the 31 st International Workshop on Surfactant \\ Replacement, Naples, June 3-4, 2016
}

The first Sharing Progress in Neonatology (SPIN) meeting incorporating the 31st International Workshop on Surfactant Replacement took place in Naples from June 3-4, 2016. It is fitting that this meeting should be held in Italy where the surfactant poractant alfa is manufactured for the treatment of preterm infants with respiratory distress syndrome worldwide [1]. Naples is Italy's third largest city after Rome and Milan. It is also famous for being one of the oldest cities in the world with great artistic merits.

The meeting started with the 8th Bengt Robertson Memorial Lecture given by Virgilio P. Carnielli from Ancona, Italy. His lecture was entitled 'Neonatal Respiratory Diseases in the Newborn Infant: Novel Insights from Stable Isotope Tracer Studies' [2]. Apart from respiratory distress syndrome, which is due to a primary deficiency of pulmonary surfactant, the pathogenesis of a variety of other neonatal respiratory disorders may involve secondary surfactant dysfunction. Studies by Carnielli and his colleagues using stable isotope tracers have increased our understanding of surfactant metabolism in many of these respiratory disorders of the newborn, including pneumo- nia, meconium aspiration syndrome and congenital diaphragmatic hernia. Results from these studies may lead to a widening of the clinical indications for surfactant therapy, something that would have greatly pleased Bengt Robertson, in whose name the lecture was given.

The second invited speaker was Robin H. Steinhorn from Washington, D.C., USA, who discussed advances in the pathogenesis and treatment of neonatal pulmonary hypertension [3]. Persistent pulmonary hypertension of the newborn is more common than realised and affects both term and preterm infants. Although there have been numerous recent therapeutic advances in the past decade, there is still no magic bullet. Once the mainstay of treatment to cause pulmonary vasodilatation, oxygen is now known to have both risks and benefits. Exogenous surfactant and inhaled nitric oxide may be useful for less severe pulmonary hypertension, and both reduce the need for extracorporeal membrane oxygenation. Other drugs with potential to benefit infants with pulmonary hypertension include milrinone, sildenafil and hydrocortisone. Steinhorn concluded that continued laboratory and clinical investigation will be needed

\section{KARGER}

E-Mail karger@karger.com

www.karger.com/neo
(C) 2016 S. Karger AG, Basel

1661-7800/16/1094-0322\$39.50/0 
to optimise treatment and improve outcomes of infants with pulmonary hypertension.

Donna M. Ferreiro from San Francisco, USA, discussed imaging of neonates with acquired perinatal brain injury in an insightful talk entitled 'The Vulnerable Newborn Brain: Imaging Patterns of Acquired Perinatal Injury' [4]. In the past two decades imaging techniques have improved to allow much better visualisation of the newborn brain, enabling understanding of mechanisms of injury and guiding diagnosis and treatment. In the term infant, the brain is susceptible to hypoxia-ischaemia, hypoglycaemia and hyperbilirubinaemia, each with a unique pattern of injury. Stroke is more common than previously suspected and infections may produce distinct patterns of white matter injury. The preterm infant's brain is particularly prone to white matter injury, and cerebellar haemorrhage is increasingly being recognised as a common occurrence. Cerebellar growth is affected by intraventricular haemorrhage, drugs and placental pathology. Ferreiro concluded that acquired perinatal brain injuries can have lifelong devastating consequences, so the search for therapies must continue.

David G. Sweet from Belfast presented the most recent update of the European consensus guidelines for the management of respiratory distress syndrome. These guidelines were first developed in 2007 [5] by an international team of neonatologists for the European Association of Perinatal Medicine and have been updated every 3 years: 2010 [6] and 2013 [7], to keep up to date with progress in the field. The present update will be published later this year.

Ben J. Stenson from Edinburgh spoke on the still controversial topic of oxygen saturation targets for preterm infants [8]. Excessive oxygen is a major cause of retinopathy and its restriction reduces the risk of this complication of prematurity. However, it seems that restriction of oxygen has its problems and may be associated with increased neonatal mortality, which has led to changes in recommended oxygen saturation targets for preterm babies [9]. Stenson reported the findings of the recently published BOOST-II trials from Australia and the UK [10] in which use of an oxygen saturation target range of $85-89 \%$ versus $91-95 \%$ resulted in non-significantly higher rates of death or disability at 2 years in each trial. However, there were significantly increased risks of this combined outcome and of death alone in post hoc combined analyses [10]. Unfortunately, the solution remains unclear; however, the proposed $\mathrm{NeOProM}$ prospective individual patient data meta-analysis may help to clarify matters [11].
The next two invited speakers from Italy discussed different forms of non-invasive ventilation $[12,13]$. Corrado Moretti from Rome spoke about synchronised intermittent positive pressure ventilation, concentrating on technical issues and clinical outcomes, whereas Gianluca Lista from Milan discussed the place of sustained inflation in the delivery room management of preterm infants. Avoiding mechanical ventilation is a critical goal in reducing the incidence of bronchopulmonary dysplasia. To this end a number of means of non-invasive respiratory support have been developed. In general, the newer modes of non-invasive ventilation are more effective than nasal continuous positive airway pressure in reducing extubation failure, and may also have a role as primary support to manage respiratory distress syndrome after surfactant therapy and for treatment of apnoea of prematurity. In the delivery room in order to prevent lung injury and to enhance the success of continuous positive airway pressure, sustained inflation by face mask or nasopharyngeal tube (20-25 $\mathrm{cm} \mathrm{H}_{2} \mathrm{O}$ for 10-15 s) has recently been suggested to establish an early functional residual capacity. Studies to date have produced conflicting results and Lista was cautious about recommending its use in routine clinical practice.

Rangasamy Ramanathan from Los Angeles, Calif., USA, reviewed therapeutic strategies for retinopathy of prematurity (ROP) [14]. He believes that understanding the pathophysiology of ROP is critical in the planning of appropriate therapeutic interventions. In phase I ROP there is vaso-obliteration soon after birth due to a marked decrease in vascular endothelial growth factor (VEGF) and insulin-like growth factor. In phase II ROP, beginning at about 33 weeks' postmenstrual age, VEGF levels increase especially when there has been retinal hypoxia leading to abnormal vasoproliferation. Ramanathan proposed that oxygen saturation targets should vary according to the phase of ROP, so that a lower saturation could be used during phase I, whereas higher target oxygen saturation may be effective in reducing rates of disabling ROP in phase II. This theory will need to be tested in prospective randomised controlled trials [8]. Other therapeutic agents being studied include insulin-like growth factor-1 and propranolol. For advanced ROP, laser ablation of avascular retina or intravitreal injection of an antiVEGF antibody, such as bevacizumab, and vitrectomy are used to protect central vision and retinal detachment.

The final talk of the SPIN Meeting was by Won Soon Park from Seoul, who discussed stem cell treatment for neonatal brain disorders [15]. This presentation was a logical continuation of Ferreiro's talk, who had set the 
scene by explaining the vulnerability of the neonatal brain [4]. Stem cell therapy is a promising novel therapy for neonatal brain injury resulting from intraventricular haemorrhage and hypoxia-ischaemia. Park presented preclinical data, covering important issues for clinical translation such as cell type, route of administration, dose and timing of stem cell therapy, and translation of these preclinical results into clinical trials.

The SPIN Update comprised four excellent talks on important topics in neonatology. Pierre Gressens from Paris discussed controversies in preterm brain injury, Petra Huppi from Geneva presented the effects of fetal growth retardation on brain structure and neurodevelopmental outcome, Karel Allegaert from Leuven talked about adverse drug reactions in the neonate and Francesco Raimondi from Naples answered the question: 'Is ultrasound useful in the diagnosis of newborn lung disease?'

The SPIN meeting also comprised 18 short oral communications and 24 poster presentations. Some of the review papers from the meeting and the free oral communications are published in this issue of Neonatology. We would like remember again Bengt Robertson who found- ed this series of workshops in 1986 and was the architect of our understanding of neonatal RDS and its treatment with surfactant [16]. He would be delighted to see how workshops on surfactant have evolved into a meeting that now shares progress in neonatology with a much wider audience. The second SPIN meeting is scheduled to be in Dublin in 2017.

Giuseppe Buonocore, Siena
Tore Curstedt, Stockholm
Henry L. Halliday, Belfast
Mikko Hallman, Oulu
Ola D. Saugstad, Oslo
Christian P. Speer, Würzburg

\section{Disclosure Statement}

The scientific program was arranged by the Scientific Committee without interference from the sponsors. All members of the Scientific Committee are or have been consultants to Chiesi Farmaceutici. The content of the meeting and workshop reflects the scientific opinions of the individual presenters and not the sponsor or its partners.

\section{References}

1 Curstedt T, Halliday HL, Speer CP: A unique story in neonatal research: the development of a porcine surfactant. Neonatology 2015; 107:321-329.

2 Carnielli VP, Giorgetti C, Simonato M, Vedovelli L, Cogo P: Neonatal respiratory diseases in the newborn infant: novel insights from stable isotope tracer studies. Neonatology 2016;109:325-333.

3 Steinhorn RH: Advances in neonatal pulmonary hypertension. Neonatology 2016:109: 334-344.

4 Ferriero DM: The vulnerable newborn brain: imaging patterns of acquired perinatal injury. Neonatology 2016;109:345-351.

-5 Sweet D, Bevilacqua G, Carnielli V, Greisen G, Plavka R, Saugstad OD, Simeoni U, Speer CP, Valls-i-Soler A, Halliday H; Working Group on Prematurity of the World Association of Perinatal Medicine; European Association of Perinatal Medicine: European consensus guidelines on the management of respiratory distress syndrome. J Perinat Med 2007;35:175-186.
6 Sweet DG, Carnielli V, Greisen G, Hallman M, Ozek E, Plavka R, Saugstad OD, Simeoni U, Speer CP, Halliday HL; European Association of Perinatal Medicine: European consensus guidelines on the management of neonatal respiratory distress syndrome in preterm infants - 2010 update. Neonatology 2010;97: 402-417.

-7 Sweet DG, Carnielli V, Greisen G, Hallman M, Ozek E, Plavka R, Saugstad OD, Simeoni U, Speer CP, Vento M, Halliday HL; European Association of Perinatal Medicine: European consensus guidelines on the management of neonatal respiratory distress syndrome in preterm infants - 2013 update. Neonatology 2013;103:353-368.

8 Stenson BJ: Oxygen saturation targets for extremely preterm infants after the NeOProM trials. Neonatology 2016;109:352-358.

-9 Saugstad OD, Speer CP, Halliday HL: Oxygen saturation in immature babies: revisited with updated recommendations. Neonatology 2011;100:217-218.

$\rightarrow 10$ The BOOST-II Australia and United Kingdom Collaborative Groups: Outcomes of two trials of oxygen-saturation targets in preterm infants. N Engl J Med 2016;374:749-760.
11 Askie LM, Brocklehurst P, Darlow BA, Finer N, Schmidt B, Tarnow-Mordi W: NeOProM: Neonatal Oxygenation Prospective Metaanalysis Collaboration study protocol. BMC Pediatr 2011;11:6.

12 Moretti C, Gizzi C, Montecchia F, Barbàra CS, Midulla F, Sanchez-Luna M, Papoff P: Synchronized nasal intermittent positive pressure ventilation of the newborn: technical issues and clinical results. Neonatology 2016; 109:359-365.

13 Lista G, La Verde PA, Castoldi F: Sustained inflation and its role in the delivery room management of preterm infants. Neonatology 2016;109:366-368.

14 Cayabyab R, Ramanathan R: Retinopathy of prematurity: therapeutic strategies based on pathophysiology. Neonatology 2016; 109: 369-376.

15 Ahn SY, Chang YS, Park WS: Stem cells for neonatal brain disorders. Neonatology 2016; 109:377-383.

16 Halliday HL, Speer CP: Bengt Robertson (1935-2008): a pioneer and leader in surfactant research. Neonatology 2009;95:VI-VII. 